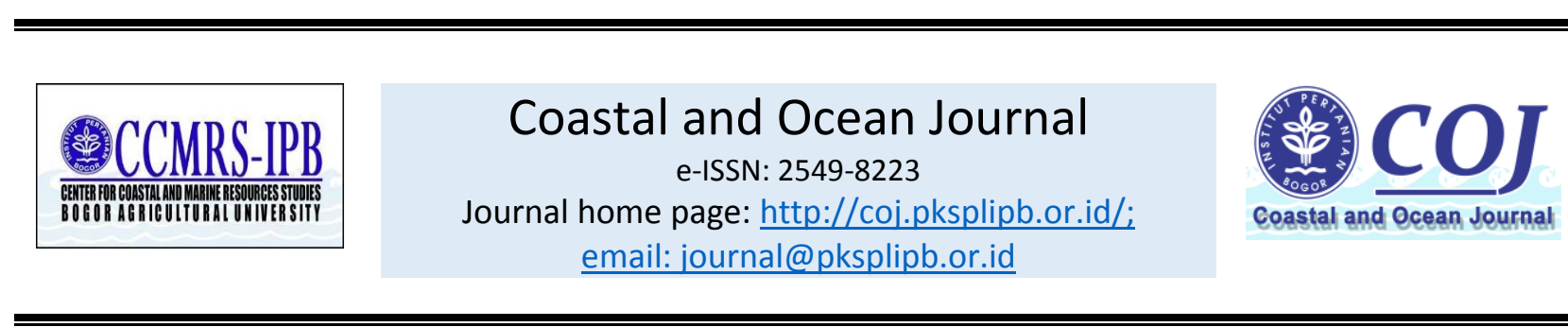

\title{
KEBUTUHAN PENGELOLAAN WISATA DI PULAU GILI LABAK, SUMENEP: EUFORIA DESTINASI WISATA BARU
}

\section{THE NEEDS OF TOURISM MANAGEMENT ON GILI LABAK ISLAND, SUMENEP: THE EUPHORIA OF NEW TOURISM DESTINATION}

\author{
Fery Kurniawana ${ }^{a^{*}}$, Robba Fahrisy Darus ${ }^{b}$, Irfanudin Rizakic \\ a Pusat Kajian Sumberdaya Pesisir dan Lautan, Institut Pertanian Bogor (PKSPL-IPB) \\ b Pascasarjana Ilmu Kelautan, Fakultas Perikanan dan Ilmu Kelautan, Institut Pertanian Bogor (FPIK-IPB) \\ ${ }^{c}$ Pascasarjana Pengelolaan Sumberdaya Pesisir dan Laut, Fakultas Perikanan dan Ilmu Kelautan, Institut \\ Pertanian Bogor (FPIK-IPB) \\ *E-mail: kurniawan.madura@gmail.com
}

\begin{abstract}
Gili Labak Island has a very beautiful natural potential, both on land and sea. Location close to the mainland make this small island a new tourism destination that is in demand of local and regional travelers and able to create new economic resources. The euphoria is creating new pressures on the environment and coastal ecosystems, especially the lack of detailed tourism management on the island, so that tourists and tourism actors that come in large numbers to perform activities freely without regard to the existing the vulnerability and the carrying capacity of ecosystems. The paper focuses on the impacts and the responses of existing and needed to build sustainable tourism of small island travel. A DPSIR (drivers, pressures, states, impacts and responses) framework is used to explore the causes and consequences on coastal ecosystems of tourism activities that is not managed properly, so the management can be arranged as needed. Detailed zoning system and the ecotourism concept needs to be applied according to the vulnerability, carrying capacity and resilience of the ecosystem of the island. Increasing the capacity of the community and travel must be conducted to ensure the sustainability of tourism and the island management.
\end{abstract}

Keywords: Small island, Gili Labak Island, Tourism, Management

\section{ABSTRAK}

Pulau Gili Labak merupakan pulau dengan potensi alam yang sangat menarik di laut dan darat. Letak pulau yang berdekatan dengan daratan utama menjadikan pulau kecil ini sebagai tujuan baru wisata, sehingga meningkatkan pengunjung lokal maupun regional dan menciptakan sumber ekonomi baru. Euforia ini menciptakan tekanan baru terhadap lingkungan dan ekosistem pesisir, terutama kurangnya pengelolaan pariwisata yang terperinci di pulau ini, sehingga wisatawan dan pelaku pariwisata yang datang dalam jumlah besar melakukan aktivitas secara bebas tanpa memperhatikan adanya kerentanan dan daya dukung dari ekosistem. Paper ini fokus pada dampak dan respon yang ada dan dibutuhkan untuk membangun wisata yang berkelanjutan pada pulau-pulau kecil. Kerangka DPSIR digunakan untuk mengeksplorasi penyebab dan konsekuensi aktifitas wisata terhadap ekosistem pesisir yang tidak dikelola dengan baik, sehingga membutuhkan pengelolaan yang teratur. Sistem zonasi rinci dan konsep ekowisata perlu diterapkan sesuai dengan kerentanan, daya dukung dan ketahanan ekosistem di pulau ini. Peningkatan kapasitas masyarakat dan agen perjalanan harus dilakukan untuk menjamin wisata yang berkelanjutan dan pengelolaan pulau ini.

Kata kunci: Pulau kecil, Pulau Gili Labak, Wisata, Pengelolaan 


\section{Pendahauluan}

\subsection{Latar Belakang}

Ledakan wisatawan di Indonesia sudah terjadi sejak sekitar tahun 1980-an dan menciptakan industri wisata yang mampu menyerap banyak tenaga kerja (Booth, 1990). Selain itu, perekonomian masyarakat mulai meningkat dengan adanya kegiatan ini, terutama pada kegiatan produksi dan kesejahteraan masyarakat (Sugiyarto et al., 2003). Salah satu contoh kegiatan tersebut adalah terciptanya pengusaha-pengusaha lokal di sekitar lokasi wisata, seperti di Pulau Bali, Pulau Lombok, dan Pulau Bintan di Kepulauan Riau (Shaw dan Shaw, 1999). Sebagai negara kepulauan, Indonesia memiliki daya tarik sendiri untuk menjadikan pulau-pulau kecil sebagai tujuan wisata baru karena memiliki keindahan, eksotisme, estetika, dan alami (Daby, 2003).

Pada perspektif yang lain, kegiatan wisata juga dapat menjadi pemicu dalam konflik sosial dan penurunan kualitas lingkungan (Lopes et al., 2017). Artinya, wisata memiliki dampak negatif terhadap pulau-pulau kecil yang merupakan entitas yang rentan (Kurniawan et al., 2016a). Gossling (2002) telah mengidentifikasi konsekuensi dari wisata terhadap lingkungan, yaitu 1) tutupan dan penggunaan lahan; 2) penggunaan energi; 3) perubahan biotik dan hilangnya spesies endemik; 4) penyebaran penyakit; dan 5) perubahan pemahaman terhadap lingkungan. Perubahan penggunaan lahan yang disebabkan oleh wisata telah terjadi di Gili Matra, yang mana telah meningkat dari Tahun 2010 hingga tahun 2014 sebesar $27,43 \%$ atau 61,76 ha (Kurniawan et al., 2016b).

Penelitian Kurniawan et al. (2016a) menunjukkan bahwa kerentaan pulau kecil terhadap wisata dapat dilihat dari perubahan garis pantai, perubahan luasan terumbu karang, perubahan karang hidup, dan meningkatnya area terbangun. Jika tingkat kerentanan terus meningkat, maka keberlanjutan wisata di pulau kecil tidak dapat dicapai, dimana aktivitas wisata sangat bergantung pada kondisi ekologi yang ada, misalnya wisata selam dan snorkeling terhadap terumbu karang, rekreasi terhadap pantai, dan lain-lain. Padahal, Brauwera et al. (2017) melaporkan bahwa aktivitas wisata selam merupakan kontributor yang besar terhadap perekomonian di pulau kecil, terutama untuk destinasi wisata baru.

Euforia wisata di destinasi baru dapat menyebabkan akan terjadinya kunjungan wisatawan berlebih dan pembangunan infrastruktur pendukung yang tidak terkontrol dan teratur, terlebih untuk destinasi yang bukan merupakan area pengembangan secara khusus. Hal ini dapat berdampak buruk terhadap lingkungan karena adanya tekanantekanan baru terhadap sistem ekologi dan sosial. Kondisi tersebut diindikasikan terjadi di Pulau Gili Labak, Kabupaten Sumenep, Provinsi Jawa Timur yang menjadi destinasi baru wisata pulau kecil. Sebagai destinasi baru, ledakan pengunjung terjadi hampir di setiap akhir pekan, libur nasional, maupun libur hari besar keagamaan. Ledakan pengunjung telah merubah dan memunculkan tekanan terhadap lingkungan, kerusakan terumbu karang akibat kegiatan snorkeling dan aktivitas transportasi kapal, baik lalu lintas dan dan jangkar, terganggunya vegetasi pantai untuk kebutuhan ruang wisata, dan meningkatnya sampah. Kondisi tersebut terjadi karena belum adanya pengelolaan wisata di pulau ini, sehingga jasa perjalanan dapat dengan bebas membawa wisatawan dan pelaku-pelaku wisata membangun usahanya dimanapun mereka suka untuk mendekati objek-objek wisata tanpa mempertimbangkan dampakdampak yang ditimbulkan. Makalah ini 
akan mencoba mengidentifikasi dan menganalisis dampak dan respon yang telah dilakukan, maupun yang direkomendasikan terhadap permasalahan-permasalahn yang muncul.

\subsection{Area Studi}

Pulau Gili Labak terletak di Desa Kombang, Kecamatan Talango Kabupaten Sumenep Madura (Gambar). Pulau dengan luas \pm 5 ha ini terletak di antara $7^{\circ} 12^{\prime} 1.03^{\prime \prime}-$ $7^{\circ} 12^{\prime} 35.14^{\prime \prime}$ LS dan $114^{\circ} 2^{\prime} 35.86^{\prime \prime}-114^{\circ}$ 3'6.59" BT. Secara administrasi, pulau ini hanya terdapat satu dusun, yaitu Dusun Gili Labak, satu Rukun Tetangga (RT) dan satu Rukun Warga (RW), dan dihuni oleh sekitar 44 kepala keluarga (KK). Untuk menuju pulau ini dapat ditempuh menggunakan perahu nelayan atau agen perjalanan dengan waktu tempuh 2,5-3 jam dari 3 pelabuhan, yaitu pelabuhan Desa Tanjung di Kecamatan Saronggi, Pelabuhan Kalianget di Kecamatan Kalianget dan Pelabuhan Desa Kombang di Kecamatan Talango.

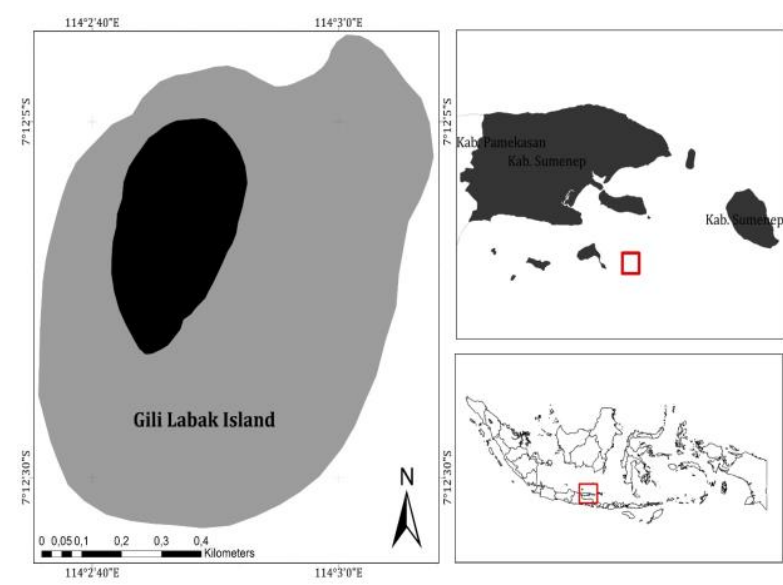

Gambar 1. Pulau Gili Labak

Mata pencaharian utama masyarakat Pulau Gili Labak adalah nelayan, sebagian kecil bekerja sebagai kuli bangunan dan karyawan toko di daratan utama. Musim sangat mempengaruhi aktivitas nelayan di pulau ini. Jika cuaca buruk, masyarakat memilih untuk berkebun dan beternak, seperti pohon kelapa, singkong dan pisang serta memelihara ayam.

Ekonomi baru di Pulau Gili Labak mulai tercipta dengan adanya kegiatan wisata bahari, yang mulai ramai sekitar tahun 2014-an. Masyarakat sudah mulai menciptakan fasilitas untuk kebutuhan pengunjung, seperti warung makan, penginapan dan alat snorkeling. Halhal tersebut merupakan dampak positif yang didapatkan oleh masyarakat pulau, dan terus meningkatkan pelayanan dan promosi wisata ke Pulau Gili Labak.

\section{Metode}

Studi ini menggunakan pendekatan kerangka DPSIR untuk mengidentifikasi, menganalisis dan mengevaluasi permasalahan yang terjadi di lingkungan Pulau Gili Labak. Borja et al. (2006) menggunakan pendekatan DPSIR untuk mengidentifikasi kegagalan sistem dalam mencapai status ekologi yang baik. Kerusakan lingkungan, seperti deforestasi dan hilangnya keanekaragaman hayati dapat juga diidentifikasi menggunakan pendekatan DPSIR (Sarminn et al., 2016; Spangenberg et al., 2009). Kerangka DPSIR ini telah dimodifikasi oleh European Environment Agency (EFA) untuk mendeskripsikan sebuah permasalahan, konsekuensi dan respon terhadap perubahan secara sistematis (Atkins et al., 2011). Respon ini yang menjadi titik balik untuk menyelesaikan atau mengurangi terhadap Pressure dan Impact yang disebabkan oleh Drivers (Gambar).

Kerangka DPSIR juga mendeskripiskan faktor-faktor sosialekonomi dan budaya masyarakat lokal yang dapat menyebabkan tekanan terhadap lingkungan pesisir dan pulaupulau kecil. Tekanan itu berupa besarnya jumlah wisatawan yang diakibatkan destinasi wisata baru di wilayah studi, sehingga dapat menyebabkan tekanan terhadap sumberdaya alam, bahkan hilangnya keanekaragaman hayati di Pulau 
Gili Labak. Hal ini akan berdampak pada ketidakberlanjutan wisata di pulau ini. Situasi ini perlu direspon oleh masyarakat ataupun pemerintah untuk menyelesaikan dampak negatif dan menyelamatkan dampak postif bagi masyarakat dan keanekaragaman hayati di pulau ini.

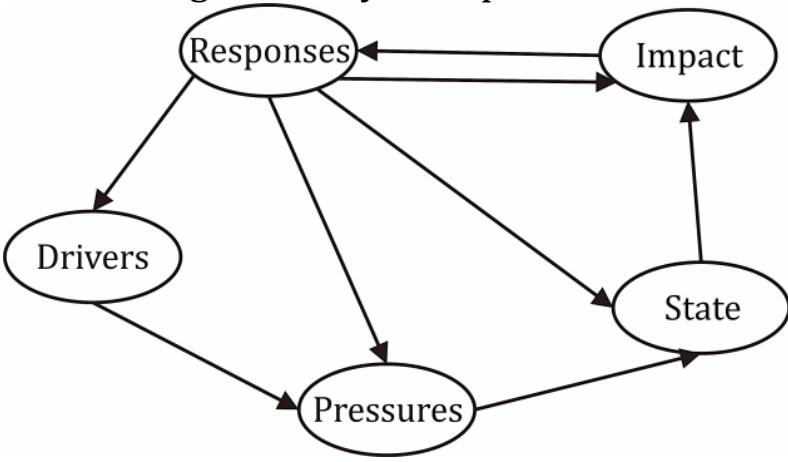

Gambar 2. Model DPSIR (Maxim et al., 2009)

\section{Hasil dan Pembahasan}

\subsection{Kondisi Pulau Gili Labak}

1) Faktor Penggerak (Drivers)

Faktor penggerak perubahan di Pulau Gili Labak adalah wisatawan dan penduduk. Pulau Gili Labak mulai dipromosikan oleh warga setempat sebagai destinasi wisata baru dengan potensi keindahan alam berupa pantai berpasir putih dan ekosistem terumbu karang sejak tahun 2012. Promosi dilakukan menggunakan media elektronik, utamanya sosial media, dan media cetak, seperti koran. Promosi tersebut sangat efektif dan mampu menarik minat wisatan.

Pertengahan tahun 2014 merupakan awal pulau ini dikunjungi wisatawan dalam jumlah besar. Meskipun belum ada fasilitas dan sarana prasarana wisata yang memadai, tetapi permintaan wisatawan untuk berkunjung semakin banyak, terutama saat akhir pekan, libur nasiona dan hari-hari besar keagamaan. Peningkatan minat wisata menyebabkan banyak bermunculan agen wisata dan agen perjalanan yang mempromosikan dan membuka paket-paket wisata ke pulau ini. Dan ini menjadi peluang untuk menciptakan sumber ekonomi baru dari sektor wisata, khususnya Kabupaten Sumenep, sehingga memicu migrasi penduduk untuk membuka peluang usaha di pulau tersebut.

2) Tekanan (Pressures)

Jumlah wisatawan dan penduduk semakin meningkat seiring semakin populer wisata di pulau tersebut. Belum adanya rencana pengelolaan wisata pulau membuat munculnya tekanan-tekanan terhadap munculnya tekanan-tekanan terhadap lingkungan dan ekosistem pulau. Tekanan-tekanan yang ada dipicu oleh meningkatnya lalu lintas kapal, pencemaran, aktivitas wisata, dan alih fungsi lahan. Selain itu, tingkat kesadaran pelaku wisata, penduduk dan wisatawan menambah rumit permasalah yang ada, seperti labuh jangkar di area terumbu karang, membuang sampah di sembarang tempat, perilaku wisatawan yang tidak konservatif, terutama saat snorkeling yang mengakibatkan rusaknya terumbu karang karena fin, jamahan tangan dan injakan, dan pembangunan pemukiman, usaha wisata dan sarana prasarana keras penunjang wisata.

3) Status (State)

Kondisi yang ada telah mempengaruhi perubahan status Pulau Gili Labak. Saat ini, wisata telah membuat rusaknya terumbu karang, meningkatnya limbah dan sampah, berkurangnya ruang terbuka, dan menurunnya estetika pulau.

4) Dampak (Impacts)

Jika perubahan status terjadi terus menerus ke arah yang negatif, maka dampak negatif yang akan ditimbulkan adalah hilangnya biodiversitas ekosistem terumbu karang, menurunnya fungsi habitat dan sumberdaya pulau, dan konflik ruang dan sosial. Hal ini akan menyebabkan wisata di Gili Labak tidak berlanjutan. 

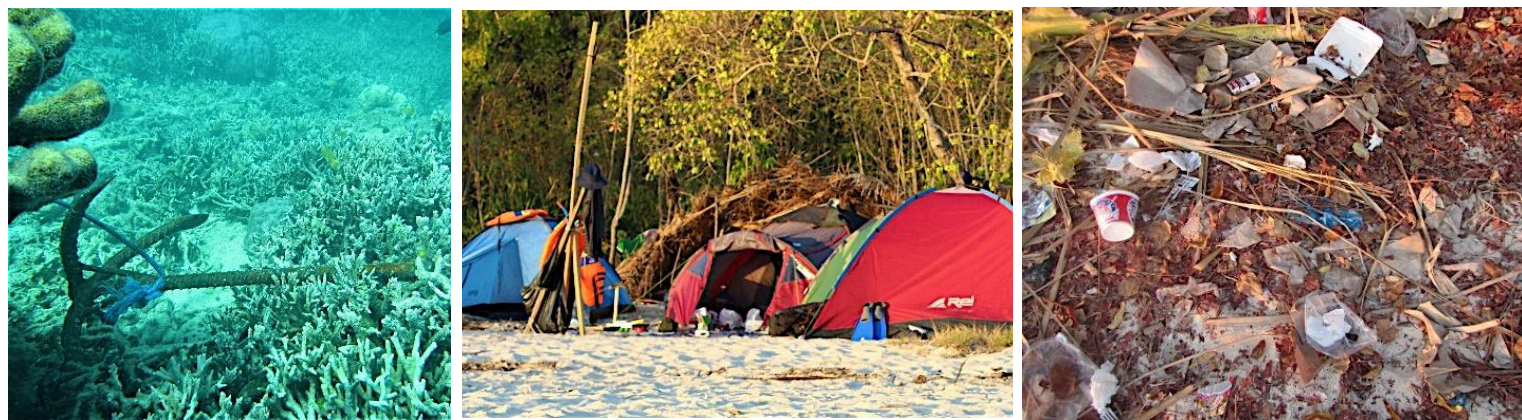

Gambar 3. Beberapa tekanan-tekanan yang muncul dan mempengaruhi perubahan status lingkungan Pulau Gili Labak

5) Respon yang Dilakukan (Responses existing)

Beberapa respon yang telah dilakukan, meliputi: (a) kegiatan bersih pantai untuk mengurangi sampah di lingkungan pantai; (b) pembuatan terumbu karang buatan (artificial reef) oleh Dinas Lingkungan Hidup Kabupaten Sumenep; dan (c) pembangunan fasilitas dan sarana prasarana penunjang wisata, meliputi: pembuatan toilet umum, menyediakan tempat sampah, dan pembuatan papan himbaun untuk kampanye penyadartahuan, seperti himbauan untuk menjaga kebersihan pantai.

1) Bersih pantai

Kegiatan bersih-bersih pantai dilakukan oleh masyarakat pulau untuk mengurangi jumlah sampah. Kegiatan ini tidak menjadi agenda khusus dan bersifat sukarela. Adanya kegiatan ini diharapkan dapat tetap menjaga kebersihan pantai, sehingga pengunjung merasa senang menikmati pulau. Sampah yang telah dikumpulkan dari kegiatan ini dikubur dan dibakar di pulau, tanpa ada pengelolaan lanjutan. Selain itu, kegiatan ini masih sebatas di lingkungan pantai, sedangkan untuk bawah laut belum dilakukan. Upaya ini dianggap belum efektif dalam mengurangi sampah, terutama yang masuk ke ekosistem terumbu karang.
2) Pembuatan terumbu karang buatan Pembuatan terumbu karang buatan dilakukan oleh Dinas Lingkungan Hidup Kabupaten Sumenep yang terbuat dari rangka beton. Kondisi terakhir terumbu buatan ini cukup bagus karena sudah banyak ditumbuhi oleh karang, meskipun peletakannya tidak teratur. Lokasi terumbu buatan ini hanya berada di satu titik saja, sehingga belum banyak mengurangi ancaman terhadap ekosistem terumbu karang dan mampu menyelesaikan masalah yang ada. Selain itu, terumbu buatan ini tidak dapat dimanfaatkan sebagai objek wisata karena substrat dasarnya pasir, sehingga sering terjadi pengadukan, baik secara alami maupun ketika ada penyelam.

3) Pembangunan fasilitas dan sarana prasarana penunjang wisata

Toilet umum merupakan solusi untuk menjaga kebersihan, keindahan dan kesehatan lingkungan pantai dan perairan. Toilet umum juga menjadi solusi efektif untuk mengurangi pencemaran yang diakibatkan oleh masyarakat dan wisatawan (limbah organik). Untuk mengurangi jumlah sampah, maka disediakan tempat sampah. Tetapi, adanya tempat sampah belum mampu menyelesaikan masalah sampah karena tingkat kesadaran wisatawan dan pelaku wisata yang 
kurang untuk membuang sampah pada tempatnya.

Upaya penyadartahuan dilakukan dengan membuat papan himbauan dan kampanye lingkungan. Keberadaan papan himabuan tidak memberikan dampak positif terhadap ekosistem pesisir. Sampah masih banyak ditemukan di daerah pantai maupun ekosistem terumbu karang. Selain itu, kebiasan waisatawan yang tidak konservatif terus terjadi dan menjadi ancaman yang sangat serius. Hal ini disebabkan juga tidak adanya edukasi dari pihak penyedia jasa wisata saat berwisata di Pulau Gili Labak.

\subsection{Kebutuhan terhadap Pengelolaan Wisata}

Berdasarkan respon-respon yang ada dan kondisi yang ada di Pulau Gili Labak, dirasa belum mampu mengurangi tekanan, megembalikan status dan memitigasi dampak yang ada. Hal ini dikarenakan respon yang ada belum menyentuh langsung permasalahan yang ada dari faktor-faktor pendorongnya. Beberapa respon yang perlu dilakukan sebagai kebutuhan pengelolaan itu meliputi: pembuatan sistem zonasi rinci, rehabilitasi terumbu karang, penerapan konsep ekowisata (Gambar 6). Respon-respon tersebut merupakan arahan pelengkap dengan tetap melakukan dan meningkatkan upaya-upaya yang telah dilakukan sebelumnya.

\section{1) Sistem zonasi yang rinci}

Sistem zonasi harus dibuat secara rinci untuk mengatur semua bentuk pemanfaatan ruang dan aktivitas yang ada didalamnya. Artinya, pembuatan sistem zonasi ini juga mencakup rencana pengelolaan di dalamnya, yang mempertimbangkan konektivitas antar zonasi dan antara perairan dan daratan. Beberapa zona yang perlu dipertimbangkan ada, meliputi:

a) Zona wisata (pemanfaatan)

Zona ini pengatur dimana lokasi yang boleh ada aktivitas wisata, dengan kriteria mencakup preferensi pengunjung, kategori pengunjung, kerentanan ekosistem sebagai objek, sarana prasana yang dibutuhkan serta, dan keamanan. Salah satu contoh yang bisa dilakukan, seperti aktivitas snorkeling boleh dilakukan pada kedalaman di atas 2 meter saat surut terendah, menggunakan pelampung dan di lokasi terumbu karang dengan jenis yang tidak sensitif (dominan karang masif).

Hal ini dilakukan agar wisatawan yang cenderung tidak memiliki kemampuan berenang yang baik dan baru melakukan aktivitas snorkeling, tidak menginjak karang ketika tiba-tiba panik dan kelelahan, dan jika hal itu terjadi dan ada kontak dengan karang, maka dampak pada karang yang tersentuh dan terinjak fin dan kaki tidak mengalami kerusakan.

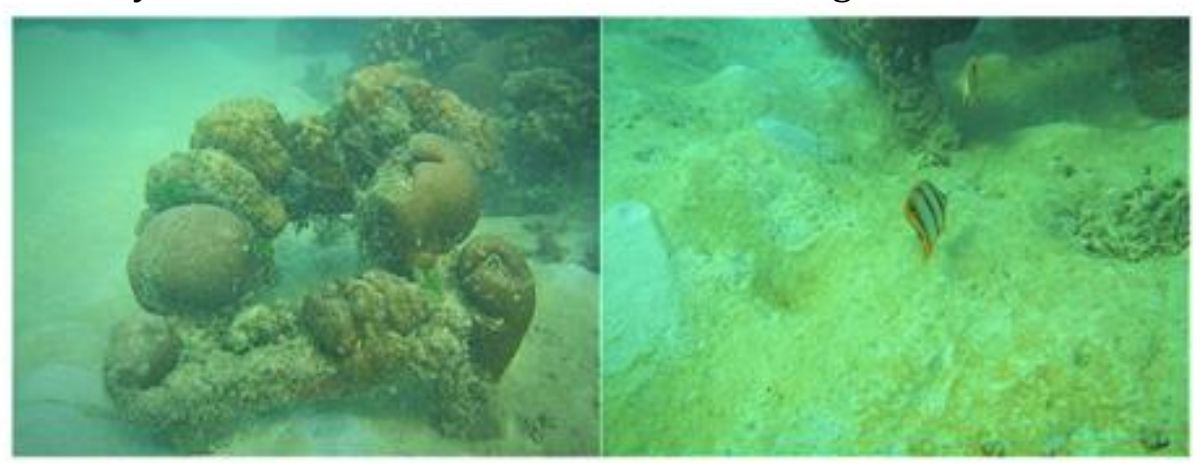

Gambar 4. Kondisi terumbu buatan di Pulau Gili Labak 
Selain itu, jika lokasi objek harus menggunakan perahu, maka dibutuhkan mooring buoy atau jangkar permanen agar kapal tidak melakukan lempar jangkar ke terumbu karang.

b) Zona pelabuhan

Tambat labuh kapal-kapal wisata hendaknya berada di satu lokasi yang terpusat, tidak berada di pusat aktivitas wisata dan yang terpenting tidak berada di lokasi ekosistem pesisir penting. Zona pelabuhan ini hendaknya juga mengatur hingga alur lalu lintas keluar masuknya kapal, agar terlihat teratur dan tidak adanya gangguan terhadap keamanan dan kenyamanan dari para wisatawan.

c) Zona perlindungan

Zona perlindungan ini umumnya dikenal sebagai zona inti atau rehabilitasi. Zona ini penting untuk menjaga keberlanjutan sumberdaya pulau dan menjadi stok plasma nutfah.

2) Rehabilitasi terumbu karang

Kerusakan terumbu karang sudah mulai terlihat dan terus bertambah dengan kondisi yang memprihatinkan. Untuk itu, rehabilitasi terumbu karang yang berkelanjutan dibutuhkan di Pulau Gili Labak. Salah satu metode rehabilitasi yang dapat digunakan adalah transplantasi karang dengan memanfaatkan terumbu karang sekitar pulau dan tanpa mendatangkan dari luar pulau. Metode transplantasi ini dapat melibatkan masyarakat dalam penanaman dan perawatannya dan biaya yang dibutuhkan relatif murah dan terjangkau, sehingga masyarakat dapat melakukan rehabilitasi ekosistem terumbu karang secara mandiri. Mengingat terumbu karang merupakan objek yang cukup populer, maka kegiatan rehabilitasi dapat menjadi aktivitas wisata, seperti adopsi karang, dan lain-lain.

3) Konsep ekowisata

Konsep ekowisata merupakan konsep yang tepat untuk diterapkan di Pulau Gili Labak untuk mengatur pemanfaatan dan aktivitas wisatawan, sehingga kelestarian sumberdaya dan daya dukung penting untuk diukur dan menjadi batasan tingkat pemanfaatan dan bentuk aktivitas yang ada. Untuk itu, prinsipprinsip ekowisata hendaknya dipertimbangkan, meliputi: wisata harus berbasis alam, mementingkan keberlanjutan ekologi, adanya pendidikan lingkungan, bernilai manfaat untuk masyarakat lokal dan menciptakan kepuasan pengunjung.

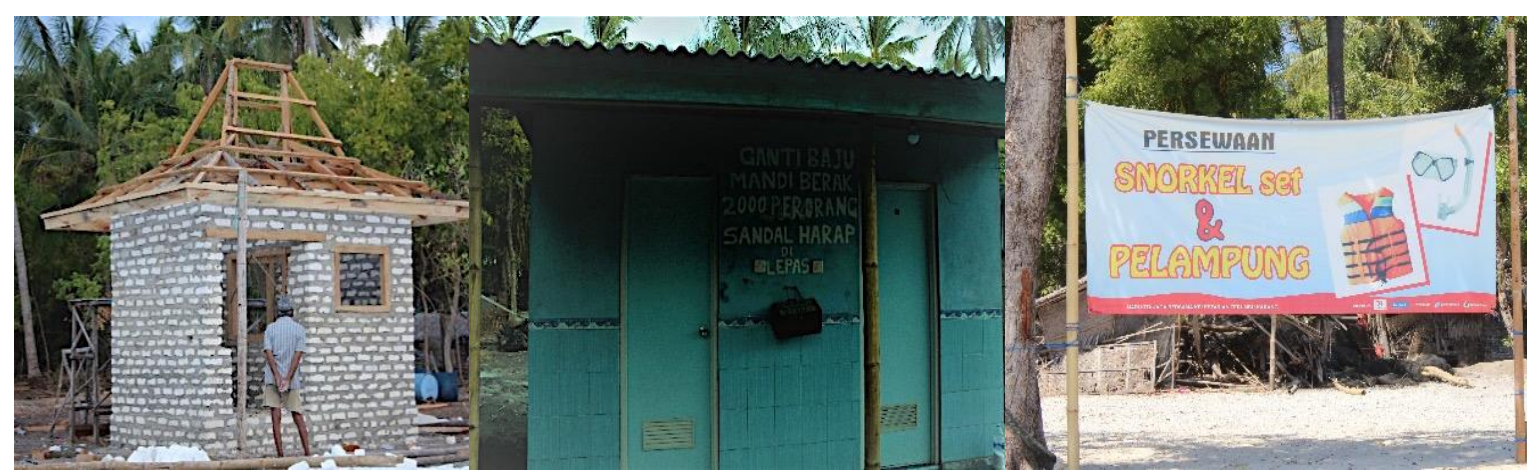

Gambar 5. Infrastruktur pendukung wisata di Pulau Gili Labak 


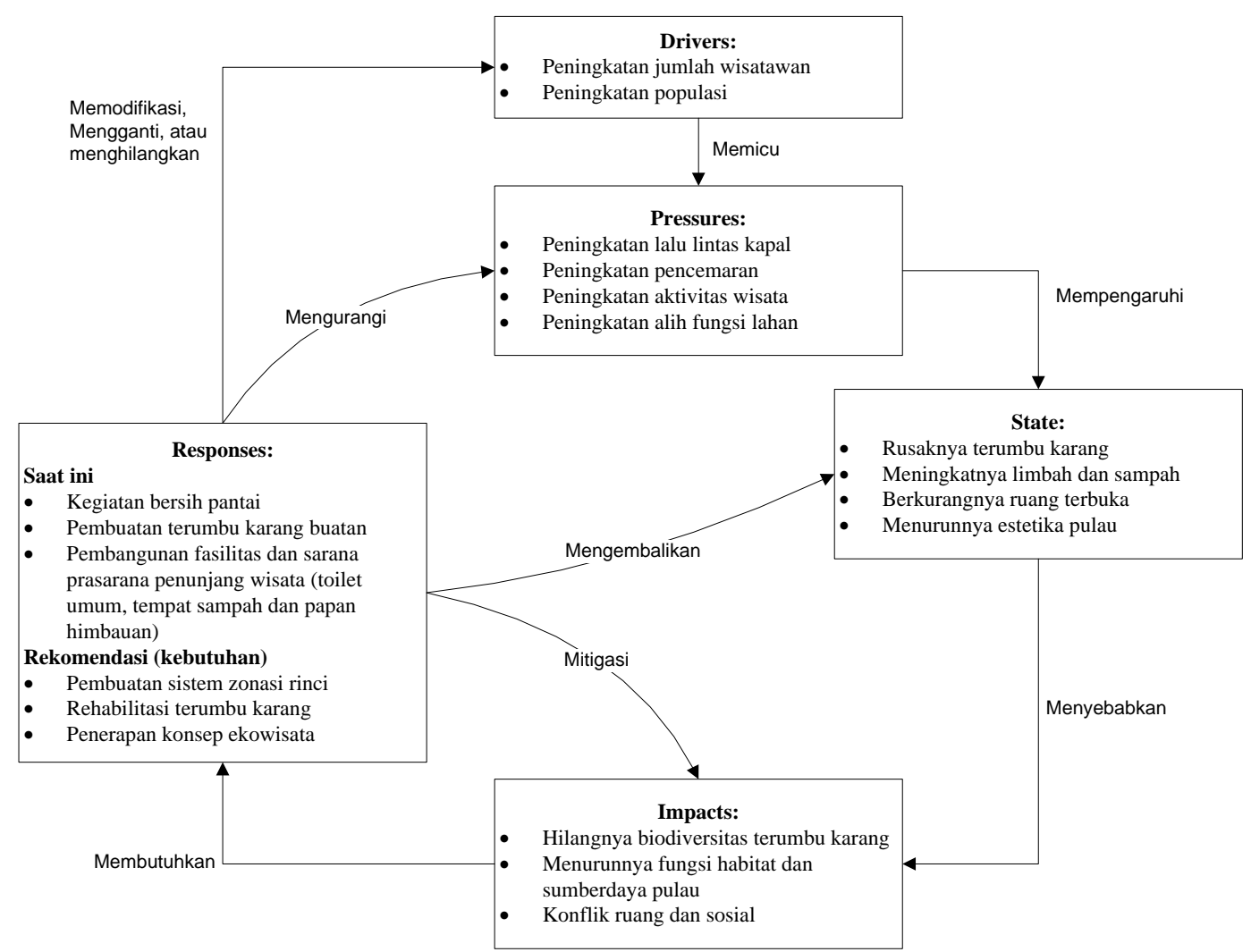

Gambar 6. Kebutuhan pengelolaan wisata di Pulau Gili Labak sebagai respon berdasarkan kerangka DPSIR

\section{Kesimpulan}

Kesimpulan dari penelitian adalah pengelolan wisata di Pulau Gili Labak dapat dilakukan dengan mengimplementasikan konsep ekowisata, sistem zonasi pemanfaatan ruang pulau, dan restorasi serta rehabilitasi ekosstem pesisir. Selain itu, pembentukan kelembagaan sebagai pengelola dan pengontrol kegiatan wisata di pulau ini sangat dibutuhkan.

\section{DAFTAR PUSTAKA}

Atkins, J.P., Burdon, D., Elliott, M., Gregory, A.J., 2011. Management of the marine environment: integrating ecosystem services and societal benefits with the DPSIR framework in a systems approach. Marine pollution bulletin 62, 215-226.
Booth, A., 1990. The Tourism Boom in Indonesia. Bulletin of Indonesian Economic Studies 26, 45-73.

Borja, Á., Galparsoro, I., Solaun, O., Muxika, I., Tello, E.M., Uriarte, A., Valencia, V., 2006. The European Water Framework Directive and the DPSIR, a methodological approach to assess the risk of failing to achieve good ecological status. Estuarine, Coastal and Shelf Science 66, 84-96.

Brauwera, M.D., Harveya, E.S., Mcllwaina, J.L., Hobbsa, J.-P.A., Jompab, J., Burtonc, M., 2017. The economic contribution of the muck dive industry to tourism in Southeast Asia. Marine Policy 83, 92-99.

Daby, D., 2003. Effects of seagrass bed removal for tourism purposes in a Mauritian Bay. Environmental Pollution 125, 313-324. 
Gossling, S., 2002. Global environmental consequences of tourism. Global Environmental Change 12, 283-302.

Kurniawan, F., Adrianto, L., Bengen, D.G., Prasetyo, L.B., 2016a. Vulnerability assessment of small islands to tourism: The case of the Marine Tourism Park of the Gili Matra Islands, Indonesia. Global Ecology and Conservation 6, 308-326.

Kurniawan, F., Adrianto, L., Bengen, D.G., Prasetyo, L.B., 2016b. Patterns of landscape change on small islands: $A$ case of Gili Matra Islands, Marine Tourism Park, Indonesia. Procedia Social and Behavioral Sciences 227, 553-559.

Lopes, P.F.M., Mendes, L., Fonseca, V., Villasante, S., 2017. Tourism as a driver of conflicts and changes in fisheries value chains in Marine Protected Areas. Journal of Environmental Management 20, 123134.
Maxim, L., Spangenberg, J.H., O'Connor, M., 2009. An analysis of risks for biodiversity under the DPSIR framework. Ecological Economics 69, 12-23.

Sarmin, N.S., Mohd Hasmadi, I., Pakhriazad, H.Z., Khairil, W.A., 2016. The DPSIR framework for causes analysis of mangrove deforestation in Johor, Malaysia. Environmental Nanotechnology, Monitoring \& Management 6, 214-218.

Shaw, B.J., Shaw, G., 1999. 'Sun, Sand and Sales': Enclave Tourism and Local Entrepreneurship in Indonesia. Current Issues in Tourism 2, 68-81.

Spangenberg, J.H., Martinez-Alier, J., Omann, I., Monterroso, I., Binimelis, R., 2009. The DPSIR scheme for analysing biodiversity loss and developing preservation strategies. Ecological Economics 69, 9-11.

Sugiyarto, G., Blake, A., Sinclair, M.T., 2003. Tourism and Globalization: Economic impact in Indonesia. Annals of Tourism Research 3, 683-701. 